\title{
SPECIMEN SIZE EFFECT ON THE CREEP OF $\mathrm{Si}_{3} \mathbf{N}_{4}{ }^{1}$
}

\author{
A. A. Wereszczak, M. K. Ferber, A. S. Barnes, ${ }^{2}$ and T. P. Kirkland \\ High Temperature Materials Laboratory \\ Oak Ridge National Laboratory \\ Oak Ridge, TN 37831-6069
}

\begin{abstract}
The effect of specimen size on the measured tensile creep behavior of a commercially available gas pressure sintered $\mathrm{Si}_{3} \mathrm{~N}_{4}$ was examined. Button-head tensile test specimens were used for the testing, and were machined to a variety of different gage section diameters (ranging from 2.5 to $6.35 \mathrm{~mm}$ ) or different surfacearea-to-volume ratios. The specimens were then creep tested at $1350^{\circ} \mathrm{C}$ and 200 $\mathrm{MPa}$ with tensile creep strain continuously measured as a function of time. The steady-state creep rate increased and the lifetime decreased with an increase in diameter (or decrease in the ratio of gage section surface area to volume). The time and specimen size dependence of transformation of a secondary phase correlated with the observed creep rate and lifetime dependence.
\end{abstract}

RECEIVED

MAR 251999

OSTI

\section{INTRODUCTION}

Several ambient air creep studies of silicon nitrides have indicated that the test specimen size may influence creep performance (e.g., minimum creep rate and creep lifetime). The existence of such a size effect would necessitate the inclusion of an extra independent variable in models used to meaningfully predict the creep performance and lifetime of complex shaped components. Creep data of PY6 (GTE Laboratories, Waltham, MA) silicon nitride generated by Wiederhorn, et al., indicated that their smaller cross-section PY6 and NT154 (Norton Advanced Ceramics, Northboro, MA) dogbone tensile test specimens $(2.5 \times 2.5 \mathrm{~mm})$ crept slower and faster than PY6 [1] and NT154 [2-3] button-head tensile test specimens

1 Research sponsored by the U. S. Department of Energy, Assistant Secretary for Energy Efficiency and Renewable Energy, Office of Industrial Technologies, as part of the Advanced Turbine Systems Program, under Contract DE-AC05-96OR22464, managed by Lockheed Martin Energy Research Corporation.

2 Presently at the Department of Materials Science and Engineering, Pennsylvania State University, University Park, PA, 16802. 


\section{DISCLAIMER}

Portions of this document may be illegible in electronic image products. Images are produced from the best available original document. 
(6.35 $\mathrm{mm}$ diameter), respectively. ${ }^{3}$ Differences in the creep rate have also been observed for SN5-L (AlliedSignal, Morristown, NJ) [4] and GN10 (AlliedSignal, Torrance, CA), see Fig. 1 [5-6], silicon nitrides when two or more different test specimen geometries were used for the testing. There are two possible explanations for these creep performance differences: (1) there is an experimental artifact being introduced that results in an apparent creep rate or lifetime functionality or (2) there is a true effect of specimen size. The present study examined both explanations and concludes that the existence of the latter is probable.

The existence of a test specimen size effect involving the creep of silicon nitride in an air environment is plausible upon first consideration. In this scenario, oxygen at sufficiently high temperatures will have a propensity to diffuse into this non-oxide ceramic. Some secondary phases in structural silicon nitride can change to different phases with greater available concentrations of oxygen in the grain boundaries. If the ratio of surface area to volume is greater for some components (or test specimens) than others, then there is a greater concentration of diffusion pathways for oxygen to diffuse into the component's center, and this could affect the rate of secondary phase transformations in such a situation. Furthermore, impurity ions in the secondary phase can diffuse to the component or test specimen's surface faster if they have less distance to travel. If the viscosity of a secondary phase glass is influenced by this impurity concentration, then the rate at which it changes (e.g., becomes more viscous) becomes more influenced by the time it takes for ions to diffuse to the surface and how far they have to travel to get there.

Limitations to the interpretation of these just described creep comparisons as a function of specimen size are that different test frames, extensometry methods, and furnaces used to generate the data, and therefore concluding that differing experimental artifacts caused the creep performance differences cannot necessarily be discounted. Additionally, PY6, NT154, SN5-L, and GN10 silicon nitrides tended to exhibit a relatively high amount of scatter in creep performance for any given single test condition (i.e., temperature and stress) even for the same specimen geometry. The present study sought to circumvent these limiting issues by measuring the creep performance of SN88 silicon nitride using button-head tensile specimens that had different gage section diameters. SN88 silicon nitride was deemed a good "model" material for this study because its creep behavior was relatively consistent and repeatable for a given test condition and specimen geometry [7].

\section{EXPERIMENTAL PROCEDURES}

SN88 silicon nitride 4 was green-state injection molded and then gas-pressure sintered. The $100 \% \beta-\mathrm{Si}_{3} \mathrm{~N}_{4}$ structure was fluxed with an ytterbium silicate. The majority of $\beta-\mathrm{Si}_{3} \mathrm{~N}_{4}$ grains were nominally equiaxed with a size distribution that ranged between approximately 0.8 to $5 \mu \mathrm{m}$. There was a small fraction of

3 Different powder lots of silicon nitride were used for the fabrication of each specimen geometry for both the PY6 and NT154, so observed creep performance differences cannot be concluded to be solely due to specimen size differences. Consequently, creep performance differences for these materials as a function of specimen size are not further discussed.

4. NGK Insulators, LTD., Nagoya, Japan, 1995 vintage. 
elongated $\beta-\mathrm{Si}_{3} \mathrm{~N}_{4}$ grains whose widths were approximately $1 \mu \mathrm{m}$ and lengths ranged between approximately $6-10 \mu \mathrm{m}$.

SN88 silicon nitride button-head tensile test specimens were machined with 2.5 , $3.0,4.0,6.0$, and $6.35 \mathrm{~mm}$ diameters. A more general portrayal of the creep performance of this material (generated with the button-head tensile test specimens) may be found elsewhere [8]. The total and gage length of all test specimens were 160 and $35 \mathrm{~mm}$, respectively. No pre-test exposures at elevated temperatures were performed prior to the application of the tensile creep stress.

All specimens were tested at $1350^{\circ} \mathrm{C}$ and $200 \mathrm{MPa}$ in tension. The specimens were cold-gripped outside a pancake, two-zone, resistance-heated furnace that was mounted on an electromechanical test frame. A high temperature contacting extensometer ( $25 \mathrm{~mm}$ gage length and $\mathrm{a} \pm 4 \mu \varepsilon$ resolution) was used to continuously measure specimen elongation during creep testing. The same test frame, furnace, and extensometer were used in all tests, and new thermocouples were installed prior to the initiation of each test. A more thorough description of the employed test equipment may be found elsewhere [9].

The microstructures of the creep tested specimens were examined with SEM, microprobe, and TEM/EDS as a function of specimen diameter. Additionally, XRD was performed as a function of specimen size and time-at-temperature (for reasons discussed later) using conical specimens (whose end-diameters bracketed those of the creep test specimens) that were aged at $1350^{\circ} \mathrm{C}$ at $3,10,30$, and 100 hours.

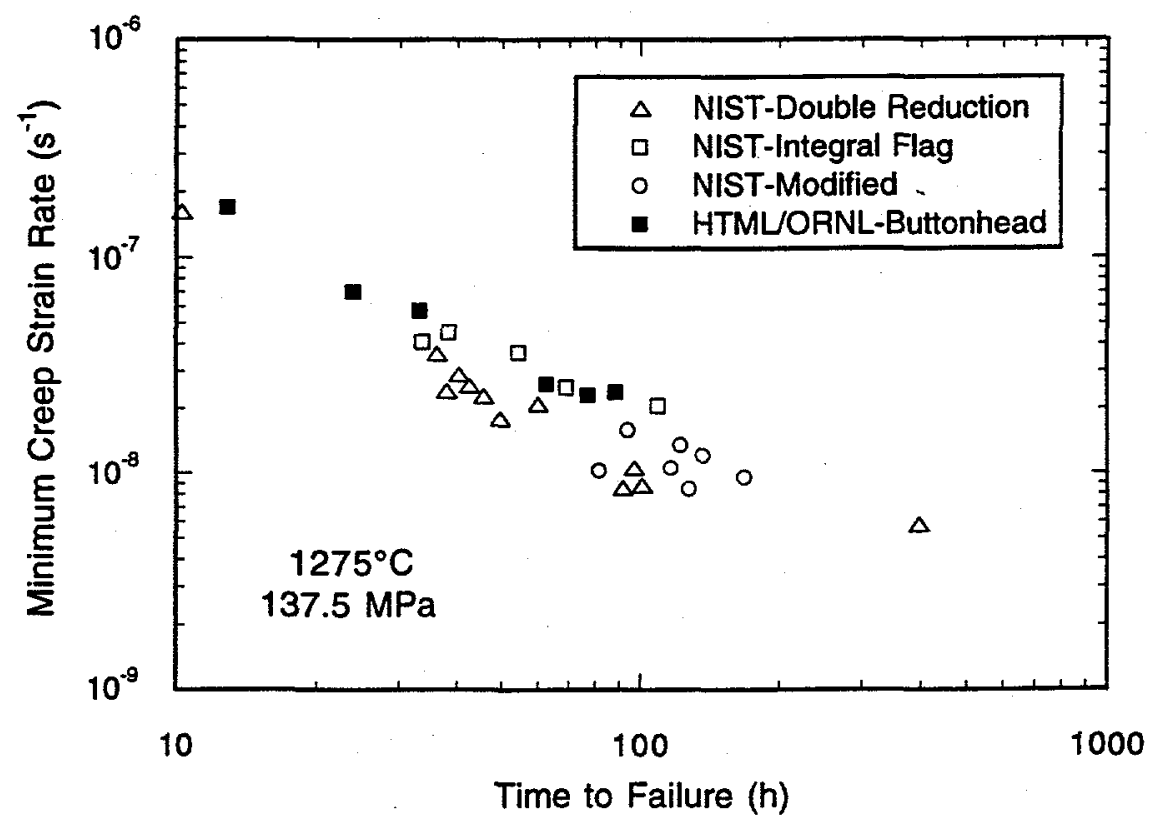

Figure 1. Smaller-sized NIST GN10 specimens $(2.5 \times 2.5 \mathrm{~mm}$ gage section cross-sections) tended to have longer time to failures and slower minimum strain rates than the larger-sized (6.35 mm diameter) ORNL button-head tensile test specimen [5-6]. 


\section{RESULTS \& DISCUSSION \\ IIIA. Creep Behavior as a Function of Specimen Size}

The steady-state creep strain rates tended to decrease and the times to failure tended to increase with decreasing test specimen diameter. Time-to-failure dependence on specimen size for SN88 has recently been reported in another study in which the authors collaborated [10]. Creep strain as a function of time for the test specimens is illustrated in Fig. 2. The creep strain histories of the five test specimens were equivalent during the first $20 \mathrm{~h}$, but those for the two largerdiameter specimens diverged from those of the three smaller-diameter specimens after that. Minimum creep rates, times to failure, and the creep strains to failure are listed in Table I for these specimens.

Diameter (i.e., the independent parameter) expressed as a ratio of the surfacearea-to-volume (SA/V) was found to be a useful parameter. Later discussion of oxygen diffusion into the silicon nitride specimens is easier to interpret by referring to the $\mathrm{SA} / \mathrm{V}$ rather than the diameter. When examining the values of these parameters as a function of $\mathrm{SA} / \mathrm{V}$, note that doubling $\mathrm{SA} / \mathrm{V}$ (e.g., decreasing diameter to 3.00 from $6.00 \mathrm{~mm}$ ) appears to be associated with the decrease in creep strain rate by one-half and the doubling of lifetime. The comparison of SA/V for button-head tensile test specimens in this study with the SA/V for typically used dogbone tensile test specimen cross-sections shows that the largest SAVV ratio in this study was still less than used for the dogbone tensile specimens employed elsewhere.

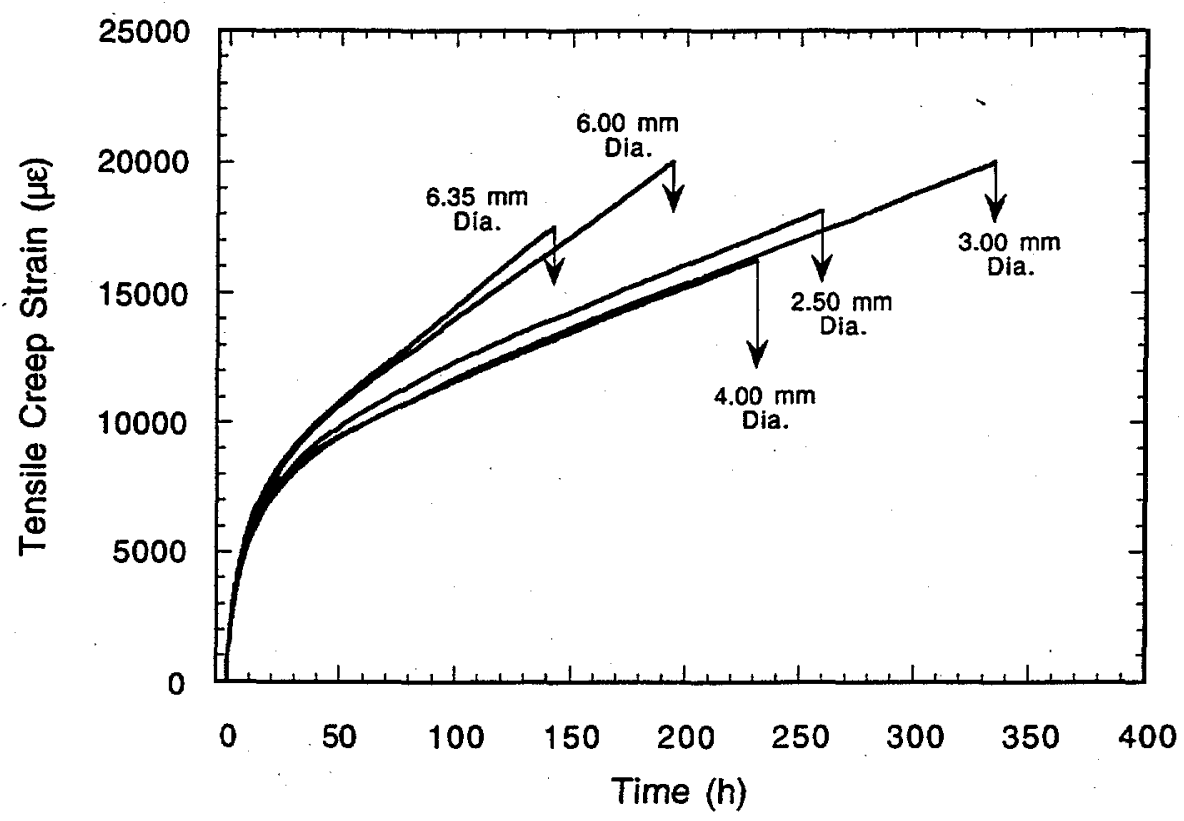

Figure 2. Creep performance was a function of specimen diameter at $1350^{\circ} \mathrm{C}$ and $200 \mathrm{MPa}$. 
Table I. Summary of $1350^{\circ} \mathrm{C} 200 \mathrm{MPa}$ creep parameter results, and surface-areato-volume comparison to some other typical specimen geometries.

\begin{tabular}{|c|c|c|c|c|}
\hline $\begin{array}{l}\text { Specimen } \\
\text { Cross- } \\
\text { Section } \\
\text { Geometry } \\
\text { (mm) }\end{array}$ & $\begin{array}{l}\text { Surface } \\
\text { Area to } \\
\text { Volume } \\
\text { Ratio } \\
\left(\mathrm{mm}^{-1}\right)\end{array}$ & $\begin{array}{c}\text { Minimum } \\
\text { Creep } \\
\text { Rate } \\
\left(\mathrm{s}^{-1}\right)\end{array}$ & $\begin{array}{l}\text { Time to } \\
\text { Failure } \\
\text { (h) }\end{array}$ & $\begin{array}{l}\text { Total } \\
\text { Creep } \\
\text { Strain to } \\
\text { Failure } \\
(\%)\end{array}$ \\
\hline $2.50 \mathrm{Dia}$. & 1.67 & $9.8 \times 10^{-9}$ & 259 & 1.816 \\
\hline 3.00 Dia. & 1.33 & $9.7 \times 10^{-9}$ & 335 & 2.001 \\
\hline $4.00 \mathrm{Dia}$. & 1.00 & $9.4 \times 10^{-9}$ & 231 & 1.624 \\
\hline 6.00 Dia. & 0.67 & $1.8 \times 10^{-8}$ & 194 & 2.003 \\
\hline 6.35 Dia. & 0.63 & $2.0 \times 10^{-8}$ & 142 & 1.754 \\
\hline $2.5 \times 2.5$ & 1.60 & & & \\
\hline $2.0 \times 2.5$ & 1.80 & & & \\
\hline $1.5 \times 2.0$ & 2.33 & & & \\
\hline
\end{tabular}

\section{IIIB. Examination of Test Temperature}

Insufficient control of furnace temperature was examined as a possible cause of the slower creep rates with the smaller diameter specimens. The water-cooled couplers that were used to grip the button-head specimen ends protected the load train components outside the furnace from heat-related damage, but they also provided a constant heat sink to the specimen. A smaller diameter specimen (i.e., a smaller volume of material in the furnace) was expected to then be at a somewhat lower temperature than a larger diameter test specimen, so interest existed to examine if this could account for their slower creep rates. The gage length surfaces of two button-head specimens (with 6.35 and $4.00 \mathrm{~mm}$ diameters) were drilled to the diametrical center at three locations; one at the specimen's axial gage section center and the other two at $\pm 15 \mathrm{~mm}$ locations from it (this $30 \mathrm{~mm}$ breadth bracketed the $25 \mathrm{~mm}$ extensometer gage length). The beaded end of six thermocouples (TCs) were embedded in each of the six holes with alumina cement. Each test specimen was then installed consecutively in the test frame and heated to the $1350^{\circ} \mathrm{C}$ setpoint as the creep specimens had been. The three thermocouple temperatures were measured in each specimen over several hours, but were found to be stable within 10 minutes of reaching the $1350^{\circ} \mathrm{C}$ furnace setpoint.

The three TCs would have each produced $1350^{\circ} \mathrm{C}$ temperatures if a uniform temperature distribution had existed; however, because of the cooling of the specimen grips, a temperature gradient was produced along the specimen length and it was exploited with these measurements. The three temperatures along the $6.35 \mathrm{~mm}$ diameter specimen's gage length were $1337^{\circ} \mathrm{C}(+15 \mathrm{~mm})$, $1351^{\circ} \mathrm{C}$ (center), and $1327^{\circ}(-15 \mathrm{~mm})$ producing an average of $1343^{\circ} \mathrm{C}$. The three temperatures along the $4.00 \mathrm{~mm}$ diameter specimen's gage length were $1333^{\circ} \mathrm{C}(+15 \mathrm{~mm}), 1342^{\circ} \mathrm{C}$ (center), and $1330^{\circ} \mathrm{C}(-15 \mathrm{~mm})$ producing an average of $1338^{\circ} \mathrm{C}$.

The temperature dependence of creep strain rate was used to numerically simulate the degree to which creep rate would be lessened due to these lower gage section 
temperatures, and to see if it could account for the measured slower creep rates. The $25 \mathrm{~mm}$ gage length was discretized into 2500 segments whose temperatures varied linearly between the temperatures measured with the thermocoupled specimens. A reference of unity creep rate was designated for a $1350^{\circ} \mathrm{C}$ uniform temperature. For an activation energy of $1100 \mathrm{~kJ} / \mathrm{mol}[6,8]$ used in the Arrhenius power-law creep rate model, the calculated ratio of creep rates was 0.728 for the $6.35 \mathrm{~mm}$-TC specimen and 0.539 for the $4.00 \mathrm{~mm}-\mathrm{TC}$ specimen. The ratio of the $4.00 \mathrm{~mm} / 6.35 \mathrm{~mm}$ calculated creep rates was therefore 0.74: this ratio for the measured creep rates (see Table I) for these two specimen sizes was 0.47 . The measured temperature along the length of the entire $4.00 \mathrm{~mm}$ diameter specimen would have needed to be $9^{\circ} \mathrm{C}$ cooler (i.e., $1324^{\circ} \mathrm{C}$ at $+15 \mathrm{~mm}, 1333^{\circ} \mathrm{C}$ at the center, and $1321^{\circ} \mathrm{C}$ at $-15 \mathrm{~mm}$ ) in order for a lower temperature to account for the slower creep rates. Results from these analyses, it is apparently implied that the existing lower temperatures during creep testing could not have solely accounted for the measured slower creep rates for the smaller-diameter specimens. Furthermore, if the lower temperatures affected the steady-state creep rate, then they did not appear to affect the accumulation of primary creep strain during the first $20 \mathrm{~h}$ of testing because all five creep curves were nearly coincident during this time.

\section{IIIC. Materials Analyses of Creep Tested Specimens \\ IIIC1. Microstructures and Composition}

The microstructures and composition of the creep tested specimens were investigated using SEM, microprobe, and TEM/EDS. Optical microscopy was also used to examine the original fracture surfaces. Polished cross-sections were examined with the SEM and microprobe, and the former was also used to observe the post-creep-testing microstructure on fracture surfaces that were generated by room-temperature refracturing. Microprobe analysis was conducted along a radius of each polished specimen using a $50 \mu \mathrm{m}$ spot size at $50 \mu \mathrm{m}$ increments. Any change in detected composition as a function of distance from the surface was compared as a function of specimen diameter. Two TEM foils per specimen were prepared from longitudinal planes; one foil came from the cross-section's center and the other came from within $100 \mu \mathrm{m}$ of the specimen's surface. EDS chemical analyses of the secondary phase were performed at several locations in each TEM foil.

No obvious differences in the microstructure or chemistry were found as a function of test specimen diameter with SEM and microprobe. However, the consistent observed trends were: (1) the oxygen-to-nitrogen ratio increased by approximately $100-150 \%$ as a consequence of creep testing, and this increase was independent of radial location and specimen diameter, ${ }^{5}(2)$ there were higher concentrations of pores/cavities in the creep tested specimens than in the as-received material, and (3) a creep damage zone at the specimens' surfaces appeared to be the cause of rupture in all specimens.

TEM/EDS provided some insights into the compositions of the secondary phases in these creep tested test specimens. A molar ratio of $\mathrm{Yb} / \mathrm{Y} \approx 2$ was found in every test specimen. The molar ratio of $\mathrm{Yb} / \mathrm{Si}$ was slightly greater than 1 in the

5. All specimens had been at $1350^{\circ} \mathrm{C}$ a minimum of $142 \mathrm{~h}$ (see Table I). 
as-received material, but ranged from 1.7 to 2 in the creep tested specimens. For the crept specimens, the molar $\mathrm{O} / \mathrm{Yb}$ ratio was approximately $50 \%$ more in the edge-located foils than in center-prepared foils. These changes are suggestive of changes in the ytterbium silicate secondary phases and oxygen penetration into the crept specimens.

\section{IIIC2. Phase Changes}

$\mathrm{X}$-ray diffractometry was conducted on a polished cross-section of the $6.35 \mathrm{~mm}$ diameter specimen gage section and its spectrum was compared to that generated from the as-received SN88. This comparison is illustrated in Fig. 3. The silicon nitride in the as-received SN88 was entirely the $\beta$ phase. There were two secondary phases in the as-received material: $\mathrm{Yb}_{2} \mathrm{Si}_{2} \mathrm{O}_{7}$ and $\mathrm{Yb}_{4} \mathrm{Si}_{2} \mathrm{~N}_{2} \mathrm{O}_{7}$ ("J phase" or phase \#4 in Fig. 3). The presence of these two phases is consistent with the obtained (composite) $\mathrm{Yb} / \mathrm{Si}$ ratio as determined with TEM/EDS. After the $6.35 \mathrm{~mm}$ specimen was crept to failure $(142 \mathrm{~h})$, the $\mathrm{J}$ phase was no longer present but the $\mathrm{Yb}_{2} \mathrm{SiO}_{5}$ phase had formed. The $\mathrm{Yb} / \mathrm{Si}$ ratio $\approx 2$ measured with TEM/EDS is consistent with the presence of this phase. The change in phases as a consequence of the high temperature exposure shows that SN88 was initially not at equilibrium with the ambient environment at $1350^{\circ} \mathrm{C}$.

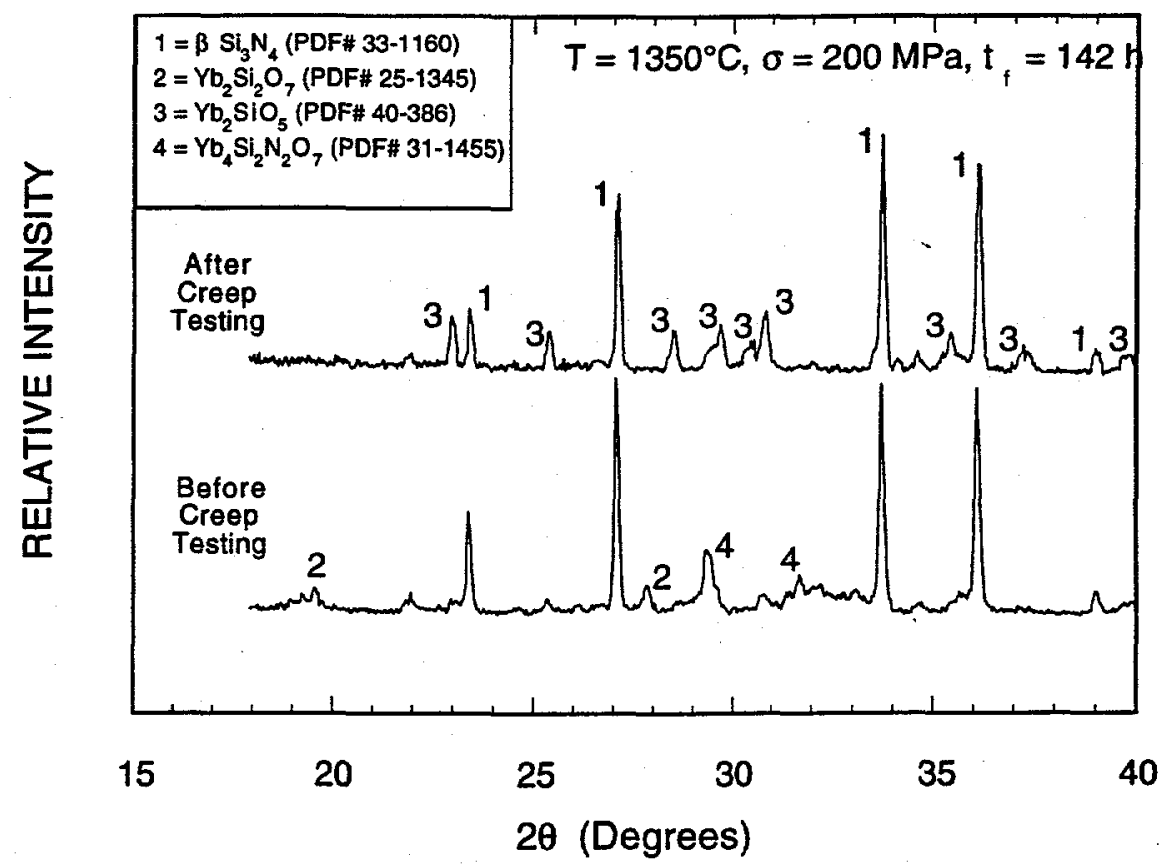

Figure 3. Phase spectra before and after creep testing at $1350^{\circ} \mathrm{C}$ and $200 \mathrm{MPa}$ for the $6.35 \mathrm{~mm}$ diameter specimen. 


\section{IIID. Phase Analysis Study of Aged SN88}

To examine the rate at which the phase changes in Fig. 3 occurred, an aging study was conducted in which the phase changes were studied as a function of time. Four conical SN88 test specimens were prepared having ends with diameters of 2 and $10 \mathrm{~mm}$ and a length of $20 \mathrm{~mm}$. All four test specimens were set in a bottom-drop furnace at $1350^{\circ} \mathrm{C}$ and one test specimen was removed after $3,10,30$, and $100 \mathrm{~h}$. The cones were then sectioned at locations to produce cross-section diameters of 3 and $6.35 \mathrm{~mm}$. The phases present at these cross-section-surfaces were then examined with XRD.

The trends in phase changes were identical to those shown in Fig. 3; however, the intensity of the major peak for the J Phase was found to decrease with time and was less for the $3 \mathrm{~mm}$ specimen than for the $6.35 \mathrm{~mm}$ specimen for equivalent times up through approximately $30 \mathrm{~h}$. The apparent complete formation of $\mathrm{Yb}_{2} \mathrm{SiO}_{5}$ had occurred in less than $3 \mathrm{~h}$ in both diameters. To semi-quantitatively examine the $J$ Phase decrease effect, the ratio of the intensity of the major $J$ Phase peak $\left(2 \theta=29.4^{\circ}\right)$ to that for the $\beta-\mathrm{Si}_{3} \mathrm{~N}_{4}$ peak $\left(2 \theta=36.1^{\circ}\right)$ was examined as a function of time for both diameters. This relationship is illustrated in Fig. 4 and shows that the $\mathrm{J}$ Phase is decreasing with time, and that between 3 and $30 \mathrm{~h}$ the J Phase content in the $3 \mathrm{~mm}$ diameter specimen is less than in the $6.35 \mathrm{~mm}$ specimen. As time continues, their ratios converge (or an equilibrium state for this phase is achieved) in the SN88. Interestingly, the time at which these differences are approximately the same correlates with the time at which the creep curves for these two specimen diameters start to diverge.

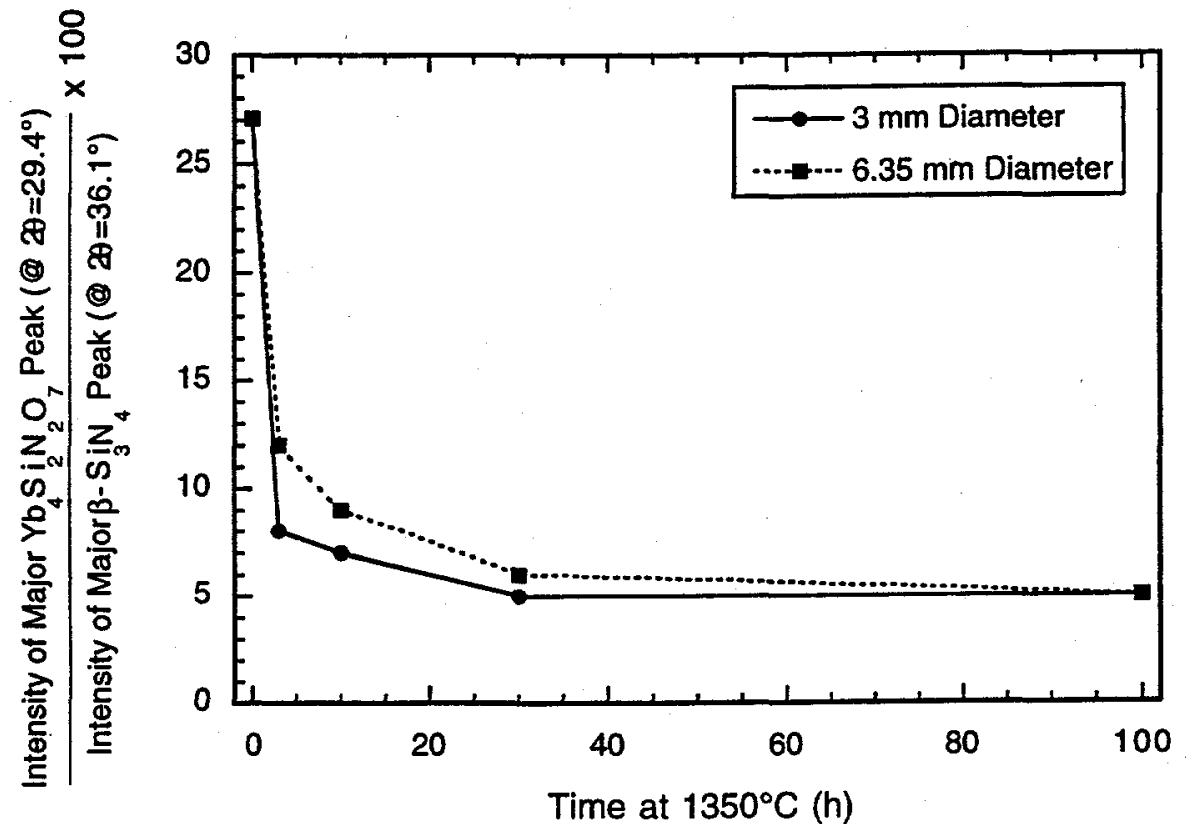

Figure 4. The J Phase content was a function of time and specimen size up through approximately 30 hours where an equilibrium state was achieved for this phase. 


\section{IIIE. Secondary Phase Equilibrium \& Specimen Size}

If oxygen diffusion into silicon nitride is a prerequisite for the achievement of secondary phase equilibrium, then specimen or component size (and shape) will affect the rate at which equilibrium is reached throughout. The formation of $\mathrm{Yb}_{2} \mathrm{SiO}_{5}$ in SN88 appears to be a consequence of the product of the J Phase and increasing concentrations of oxygen. The mechanism is not fully understood, but if this conversion process takes longer while SN88 is subjected to tensile stress, then SN88's long-term creep resistance is lessened as a consequence. This suggests that the elimination of the J Phase prior to mechanical loading at high temperatures would maximize SN88's creep resistance and lifetime.

The absence or existence of secondary phase equilibrium in other silicon nitrides has been shown to respectively result in no (or minimal) specimen size effect, or a size-effect like that exhibited by SN88 silicon nitride. NT164 (Norton Advanced Ceramics, Northboro, MA) silicon nitride contained a secondary phase that did not change with time [11] and its creep rate and lifetime incidentally were not apparently dependent on specimen size in one study [12]. SN5-L silicon nitride exhibited an apparent specimen size effect in creep and contained as-received secondary phases that changed during creep testing; however, unlike SN88, larger SN5-L tensile specimens had better creep resistance [4]. Lastly, GN10 silicon nitride contained non-equilibrated secondary phases and its creep deformation was apparently dependent on specimen size [5-6]. The SN5-L and GN10 silicon nitrides contained secondary phases that oxidized and consequently transformed to other phases with significant volume changes [13]. The results from these studies correlate with result of this study; namely, it is advantageous to choose a creep resistant silicon nitride whose secondary phases are in equilibrium and will not transform to others during mechanical loading at elevated temperatures.

\section{CONCLUSIONS}

The creep resistance and creep lifetime of SN88 silicon nitride appeared to be a function of test specimen size (or surface-area-to-volume ratio) at $1350^{\circ} \mathrm{C}$ and 200 $\mathrm{MPa}$. Oxygen diffusion into the silicon nitride appeared to be associated with the secondary phase transformation of a crystalline ytterbium silicate phase to a different one with higher oxygen content. The transformation rate of this secondary phase appeared to be a function of specimen size, and a faster transformation rate was associated with improved creep resistance and longer creep lifetimes. The results in the present study suggest that a specimen size effect on creep performance may be active if the secondary phase is not initially in equilibrium, and that its long term response will dependent on the rate at which secondary phase equilibrium is achieved.

\section{ACKNOWLEDGMENTS}

The authors wish to thank H. -T. Lin and K. C. Liu for reviewing the manuscript and for their helpful comments. Additionally, C. Rawn is thanked for the XRD testing. 


\section{REFERENCES}

[1] S. M. Wiederhorn, G. C. Quinn, and R. Krause, "Fracture Mechanism Maps: Their Applicability to Silicon Nitride," Life Prediction Methodologies and Data for Ceramic Materials, ASTM STP 1201, C. R. Brinkman and S. F. Duffy, Eds., American Society for Testing and Materials, Philadelphia, 1994.

[2] W. E. Luecke, S. M. Wiederhorn, B. J. Hockey, R. F. Krause, Jr., and G. G. Long, "Cavitation Contributes Substantially to Tensile Creep in Silicon Nitride," J. Am. Ceram. Soc. 78 2085-96 (1995).

[3] M. N. Menon, H. T. Fang, D. C. Wu, M. G. Jenkins, M. K. Ferber, K. L. More, C. R. Hubbard, and T. A. Nolan, "Creep and Stress Rupture Behavior of an Advanced Silicon Nitride: Part I, Experimental Observations," J. Am. Ceram. Soc. 77 1217-27 (1994).

[4] A. A. Wereszczak, T. P. Kirkland, H. -T. Lin, M. K. Ferber, C. -W. Li, and J. A. Goldacker, "Tensile Creep Performance of a Developmental In-Situ Reinforced Silicon Nitride," Ceram. Engrg. Sci. Proc. 18 45-55 (1997).

[5] W. E. Luecke, NIST, unpublished results.

[6] M. K. Ferber and A. A. Wereszczak, ORNL, unpublished results.

[7] W. E. Luecke and S. M. Wiederhorn, "Interlaboratory Verification of Silicon Nitride Tensile Creep Properties," J. Am. Ceram. Soc. 80 831-838 (1997).

[8] A. A. Wereszczak and T. P. Kirkland, "Creep Performance of Candidate SiC and $\mathrm{Si}_{3} \mathrm{~N}_{4}$ Materials for Land-Based, Gas Turbine Engine Components," ASME Paper 96-GT-385, ASME International Gas Turbine and Aeronautical Congress and Exposition, Birmingham, UK, June, 1996.

[9] A. A. Wereszczak, M. K. Ferber, T. P. Kirkland, K. L. More, M. R. Foley, and R. L. Yeckley, "Evolution of Stress Failure Resulting from High-Temperature Stress-Corrosion Cracking in a Hot Isostatically Pressed Silicon Nitride, J. Am. Ceram. Soc. 78 2129-40.(1995).

[10] W. E. Luecke, et al., "Report of an International Round Robin for Tensile Creep of Silicon Nitride, in preparation, 1999.

[11] A. A. Wereszczak, T. P. Kirkland, M. K. Ferber, T. R. Watkins, and R. L. Yeckley, "The Effects of Residual $\alpha$ Phase on the $1370^{\circ} \mathrm{C}$ Creep Performance of Yttria-Doped HIPed Silicon Nitride," J. Mat. Sci., 33 2053-2060 (1998).

[12] H. -T. Lin, P. F. Becher, and M. K. Ferber, "Improvement of Tensile Creep Displacement Measurements," J. Am. Ceram. Soc. 77 2767-70 (1994).

[13] F. F. Lange, S. C. Singhal, and R. C. Kuznicki, "Phase Relations and Stability Studies in the $\mathrm{Si}_{3} \mathrm{~N}_{4}-\mathrm{SiO}_{2}-\mathrm{Y}_{2} \mathrm{O}_{3}$ Pseudoternary System," J. Am. Ceram. Soc. 60 249-252 (1977). 